\title{
Construindo Objetos de Aprendizagem e pensando em Geometria ${ }^{1}$
}

\author{
Eduardo Melloni Lucchesi \\ Paula Aguiar da Silva \\ Vinícius Teixeira da Silva \\ Cristiano Lopes Lima \\ Marcus Vinicius de Azevedo Basso \\ Léa da Cruz Fagundes \\ Instituto de Matemática - Universidade Federal do Rio Grande do Sul \\ eduardo.lucchesi@gmail.com, paulaasmini@yahoo.com.br, \\ vinicius@mat.ufrgs.br, clopeslima@gmail.com, mbasso@ufrgs.br, \\ leafagun@ufrgs.br
}

\begin{abstract}
Resumo
Nesse artigo tratamos dos objetos de aprendizagem destinados ao estudo de Geometria utilizando recursos Java e Flash e analisamos a concepção pedagógica que norteia sua construção a partir das experiências e discussões da equipe ao longo da primeira fase do RIVED/Fábrica Virtual. Paralelamente apresentamos o desenvolvimento de novos recursos para comunicação digital que possibilitem implementar o trabalho de professores e alunos de graduação, geograficamente distantes, utilizando recursos telemáticos no processo de comunicação/interação entre professores/profissionais em formação e destes com alunos dos ensinos médio e fundamental.
\end{abstract}

Palavras - chave: geometria, objetos de aprendizagem, educação a distância.

Title: Constructing Learning Objects and thinking about Geometry

\begin{abstract}
:
In this article we attend to learning objects appropriated to the study of Geometry, using Java and Flash resources, and we analyze the pedagogical notion that guides its construction from the experiences and discussions of the team through the first phase of the "RIVED/Fábrica Virtual". We present the development of new digital communication resources that may enable the work of teachers and graduation students geographically distant using telematics resources in the process of communication/interaction between teachers/professional in initial formation and between these ones and high school students.
\end{abstract}

Keywords: geometry, learning objects, e-learning.

\footnotetext{
1 Trabalho vinculado ao RIVED - Secretaria de Educação a Distância - Ministério da Educação, desenvolvido sob orientação dos Profs. Marcus Vinicius de Azevedo Basso e Léa da Cruz Fagundes.

V. 4 № 2, Dezembro, 2006
} 


\section{Introdução}

Existe uma disponibilização crescente de material voltado ao estudo da geometria seja na web ou em outro meio digital. De fato, essa tendência não está restrita ao domínio da geometria muito menos ao campo da Matemática. Como o caso do Google (um dos principais sites de busca) e similares que tem seu foco justamente no armazenamento e busca de material/informação na rede. $\mathrm{O}$ dilema quantidade versus qualidade domina a paisagem. Usuários que a cada dia mudam seu perfil mais rapidamente, sua forma de lidar com as informações, meta-informações e mesmo seus relacionamentos, tem a cada dia mais dificuldade ao se depararem com os métodos ortodoxos encontrados nas escolas.

$\mathrm{Na}$ rede mundial de computadores se encontram artigos, trechos ou livros inteiros digitalizados em diferentes domínios e, não raro, material cada vez mais sofisticado. Hipertextos, ilustrações, animações ou mesmo conteúdo em enciclopédias virtuais são tentativas de se levar o conhecimento a um nível maior. A criação e aperfeiçoamento dessas e de outras ferramentas e de ambientes para trocas de informações entre usuários, seja por e-mail, chat ou fórum são condições fundamentais para que a Educação à Distância (EAD) chegue a um nível ótimo. Qual seja, a de inclusão digital, o acesso a informação, a aprendizagem, a inclusão social de fato.

Esse material, ou boa parte dele, para os que podem e têm interesse em acessá-lo, normalmente carece de um ambiente propício ou mesmo uma formatação adequada para o ensino/aprendizagem. Carece, no mínimo, de acompanhamento apropriado ou alguma forma de retorno/interação com o usuário ou entre usuários. Talvez pelo fato de não existir compromisso educacional formal na grande maioria dos casos, apenas o de divulgação, esse material pode conter incorreções às vezes sutis, às vezes mais profundas que comprometem não apenas o conteúdo como também a própria proposta de divulgação. Outros problemas seriam, a grande quantidade de informação, explicações contraditórias, conteúdo incompleto, a falta de orientação e de uma diretriz pedagógica no processo. Esses problemas conduzem, certamente, a confusão. Algumas vezes existe um tutor, mas não existe flexibilidade que torne o material ajustável à necessidade do aprendiz. Faltam, no nosso entender, ferramentas ou composição das existentes para construção do conhecimento matemático/geométrico, bem como, diversidade de objetos em nível bom ou com competências pedagógicas mínimas.

Esse é o momento da consolidação da virtualização. Da real troca de paradigma do Ensino/Aprendizagem. As mídias, software e hardware, estão chegando a uma maturidade que possibilita a criação de Objetos de Aprendizagem (OA) adequados. A nuvem de insegurança e desinformação a respeito da sua viabilidade começa a se desfazer. Não apenas em se tratando dos usuários, mas também nos ambientes governamentais que se voltam especificamente para essa realidade eminente e sem volta. Esse é o caso, por exemplo, do RIVED - Rede Interativa Virtual de Educação. Mas o processo não é apenas tecnológico. O Ensino/Aprendizagem demanda processos específicos. É aqui que vemos o diferencial na construção dos OA.

“(...) para construir conhecimento, é preciso reestruturar as significações anteriores, produzindo boas diferenciações e integrando ao sistema as novas significações. Esta integração é resultado da atividade de diferentes sistemas lógicos do sujeito, que interagem entre si e com os objetos a assimilar ou com os problemas a resolver. Finalmente, o conhecimento novo é produto de atividade intencional, interatividade 
cognitiva, interação entre os parceiros pensantes, trocas afetivas, investimento de interesses e valores. (...)” (Fagundes, 1999)

\section{Perfil do Usuário}

Inicialmente vamos tentar definir quem é nosso aprendiz, ou seja, quem estamos pensando que fará uso do material que já se começou a produzir e o que ainda se pretende construir. Quando propomos esta discussão não estamos apenas nos referindo à idade do usuário como o próprio padrão estabelecido no Design Pedagógico do RIVED recomenda. Estamos nos referindo especificamente a um mundo dominado pela alta tecnologia, pelas manipulações atômicas e relativísticas da realidade e das viagens espaciais. Um mundo globalizado em que os seres humanos se encontram cada vez mais próximos, cada vez mais conectados apesar da separação física, separação esta que vai sendo superada cada vez mais facilmente. Um mundo em que o tempo parece passar mais rápido. Onde os acontecimentos se multiplicam e a cada instante uma descoberta científica pode mudar os rumos da sociedade. Mundo que com todos esses avanços ainda não conseguiu erradicar a fome, nem o analfabetismo, nem as epidemias que volta e meia tomam conta da mídia, nem dos cataclismos e dos problemas sociais causados pela intolerância e incompreensão do homem como as guerras, o crime e as drogas.

São situações e notícias que estão nos meios de comunicação massivamente. De minuto em minuto um novo fato espoca na mídia. E, assim como muitas informações chegam a todo instante, pouco se pode aprofundar a seu respeito. Informações que, muitas vezes, já vem com a interpretação feita por algum jornalista, comentarista ou especialista no assunto em questão.

É nesse contexto que os usuários estão inseridos diariamente. Tendo a TV, como sendo um dos maiores, senão o maior meio de comunicação de massa e onde a internet ganha cada vez mais espaço. Entendemos que os Objetos de Aprendizagem não tem como e nem por que competir com a TV, pois esta se constituí em uma forma de entretenimento mas às vezes como fonte de cultura também. A diferença está na passividade da TV. Não há interação. Os tele-espectadores se habituam a receber informações que, tão rápidas quanto vem, são esquecidas. Mas, o fator interessante é que nos televisores existe a possibilidade do usuário trocar de canal a qualquer momento, de procurar o que lhe agrade. Assim como na Internet, existem opções diversas para o que se procura/deseja, de uma forma muito dinâmica, criando a sensação de poder do agente sobre o meio. O contrário pode, por esse prisma, gerar a sensação de frustração no aprendiz se ele não tiver como fazer escolhas, se não tiver possibilidade de interagir, de ser seu próprio tutor dentro de um limite pré-estabelecido para o contexto do objeto. Ao mesmo tempo, as questões que o $\mathrm{OA}$ vai propondo, devem ser suficientemente desafiadoras para esse usuário acostumado a grande quantidade de informações e suficientemente atualizadas. Esse mesmo aprendiz estaria habituado com jogos em realidades virtuais e ambientes com riqueza de detalhe e de possibilidades de interação.

\section{Desenvolvimento Tecnológico}

Devido ao atual grau de desenvolvimento tecnológico, de manipulações nanotecnológicas, muito do que apenas se imaginava como possível recurso para um OA, começa a poder estar acessível nos computadores dos usuários. Tanto pelo aumento da capacidade do hardware e do software como pela viabilidade econômica de se adquirir o equipamento mínimo, providenciar a instalação correta e a manutenção adequada.

Muito do que já se produziu e se pensou em desenvolver para os OA, que por vezes parece viável nos computadores mais poderosos dos desenvolvedores, geralmente 
encontram uma forte barreira tecnológica/econômica nas escolas com quase nenhuma verba para esse tipo de situação. Enquanto os custos de produção e fabricação de hardware vêm diminuindo, sua capacidade vem aumentando. Os processadores são muitas vezes mais rápidos dos que os de poucos anos atrás. Memórias cada vez maiores, com tempos de acesso cada vez menores, surgem a todo o momento. As dimensões dos componentes se reduzem, diminuindo as dimensões dos equipamentos, seu peso e seu consumo de energia. Os sistemas físicos de transmissão/comunicação (linhas telefônicas utilizando fibras óticas) com largura de banda impensáveis, agora chegando a lugares remotos.

Todo esse desenvolvimento de hardware, obviamente, não está sozinho. O software também se desenvolve e muito. Os programas já possuem estruturas apropriadas para aplicações de Web. Na realidade, são criados especificamente voltados para atender a essa demanda. Assim como os programas, os objetos também já incorporam algumas dessas características se tornando muito mais interessante enquanto vão se tornando reutilizáveis.

Todos esses recursos de software e hardware se usados separadamente ou todos num mesmo objeto, por si só, já trazem um acréscimo considerável a proposta de Ensino se pensarmos em termos da interface e comunicações assíncronas. Fatores muito importantes, mas, os principais pontos a serem trabalhados são o da interatividade (objeto/aprendiz) e o das comunicações síncronas (aprendiz/aprendiz, aprendiz/tutor), pois é neles que estão centrados a Aprendizagem.

Quando falamos nas melhorias possibilitadas pelos novos recursos e novas mídias, estamos falando do uso do Java e do Flash como programas mais adequados para aplicações digitais e de internet. Em particular, desenvolvemos um programa para a comunicação telemática entre os usuários do objeto que permite as trocas de fórmulas de matemática possuindo ainda a característica de ser reutilizável/reprogramável para outros fins como na química, por exemplo.

Dos muitos obstáculos que se apresentam aos alunos e professores que buscam interagir através da internet, um dos primeiros é a falta de uma ferramenta que possibilite editar e inserir fórmulas em uma sala de bate papo. Para vencer essa dificuldade desenvolvemos um programa que permite a comunicação síncrona, na forma de um chat, e no qual estão incorporados um editor de fórmulas, o que permite a utilização de expressões matemáticas e um sistema de upload de imagens, contribuindo, dessa forma, para discussões nas quais e faz necessário discutir aspecto ligados a Geometria.

\section{Quantidade x Qualidade}

A crescente e incrível quantidade de informação que toma conta de todas mídias disponíveis, ao mesmo tempo que deslumbra pelas infinitas possibilidades que parece suscitar, se mostra, por vezes, assustadora. Pela crise de gerenciamento que tanta informação pode gerar e pela, quem sabe, impossibilidade de se manter atualizado. Além do problema como o gerenciamento (encontrar/salvar) da informação, existe ainda uma outra grave questão a considerar. Qual a confiabilidade/qualidade dessa informação?

Um teste simples pode ser feito por qualquer um com acesso a rede mundial de computadores. Coloque uma palavra/assunto qualquer num dos motores de busca disponíveis (experiência que todos já devem ter feito), de preferência sobre um assunto em que se tenha conhecimento suficiente para poder analisar os resultados obtidos. $\mathrm{O}$ primeiro fato que se evidencia é a grande quantidade (se for um assunto mais comum) de páginas que aparecem contendo a palavra digitada. Sabemos que diversas opções são oferecidas para se restringir os resultados aos mais adequados. Entre alguns deles estão 
o uso de mais de uma palavra, exclusão de outras, sites mais acessados, etc. Ainda assim, não existe garantia sequer de se encontrar o que se procura. Podemos ainda mencionar um outro complicador. Quanto tempo podemos despender se não soubermos fazer um bom refinamento nas busca? Quanto mais soubermos sobre o tema em questão, mais fácil restringir a busca e assim menor o tempo para encontrar algo. Porém, normalmente se procura o que se desconhece invertendo toda a lógica anterior, aumentando o tempo necessário para tal busca.

Como tratado no item anterior sobre a tecnologia, os preços de armazenamento por bit vem caindo consideravelmente, facilitando cada vez mais, o aumento de informação disponível/publicada. Muitos dos resultados obtidos são cópias uns dos outros. Páginas que não estão atualizadas, incompletas ou simplesmente de conteúdo superficial. Acontece também com muito mais freqüência, textos duplicados, sem referência alguma ou com autoria diferente em cada site. Poucos resultados parecem ter cuidados com as referências e a bibliografia utilizada. Ainda pior que isso, informações erradas e muitas vezes contraditórias estão por toda parte. Estamos nos referindo especificamente em tratar dos casos com a Web. Por se tratar de uma das possibilidades de pesquisa mais rápida, que tem o maior retorno e que está sendo cada vez mais utilizada em todo mundo. Onde estão sendo produzidos materiais continuamente por qualquer um que tenha acesso e condições, mas, também por já estar presente em muitas escolas sendo efetivamente utilizado pelos alunos nos seus trabalhos escolares.

Acreditamos que uma das grandes questões didático-pedagógicas dos OA está justamente nas referências e na autoria do material produzido/encontrado. Quanto melhor isso for pensado, quanto mais claras e acessíveis estiverem essas referências, maior qualidade e confiabilidade o objeto terá.

\section{Construção do Conhecimento em Objetos de Geometria}

Voltados para o ensino/aprendizagem à distância estamos organizando um ambiente com diversos objetos matemáticos principalmente voltados a geometria. É importante observar que usualmente não se dá oportunidade ao aluno para qualquer escolha. Não lhe cabe tomar decisões. Pesquisas em psicologia genética, sobre o desenvolvimento da inteligência e sobre o processo de aprendizagem, evidenciam que pode haver ensino sem haver aprendizagem; que aprendizagem latu sensu se confunde com desenvolvimento; e desenvolvimento resulta em atividade operatória do sujeito, que constrói conhecimento quando está em interação com o meio, com outros sujeitos e com os objetos de conhecimento de que ele deseja se apropriar. Tais pesquisas dão a orientação necessária para que no desenvolvimento dos objetos desse tópico os estudantes tenham a oportunidade de realizar escolhas.

Em termos práticos, nossa proposta prevê que, o aluno tendo diante de si desafios ao longo da exploração de um objeto ou de um módulo de conhecimento pré-determinado, módulo esse que pode ser escolhido pelo próprio aluno. A partir dos primeiros resultados, novamente os próprios estudantes podem realizar explorações, compondo e recompondo resultados conforme o OA propõe e conforme vão assimilando conceitos e obtendo sucesso em termos de aprendizagem.

A proposta em relação aos Objetos de Aprendizagem é de que eles se apliquem a Geometria nos seus diversos níveis. Tais objetos abordam, desde construções de relações de causa e efeito até as demonstrações de teoremas. Através de jogos, animações, exemplos diversos e atividades propostas o estudante pode ir trabalhando no seu próprio ritmo. 
Nossa proposta de produção do material está estreitamente vinculada à certa dinâmica de funcionamento das disciplinas e está fundamentada em nossas concepções sobre processo de ensino e aprendizagem na modalidade EAD.

Estamos pressupondo:

- o uso de software de geometria dinâmica de domínio público

- o uso da Internet; em particular, o uso de plataforma para EAD, com recursos de fórum, chat e webfólios que se configuram como um espaço para produção de trabalhos dos alunos

Com estes pressupostos nos propomos a desenvolver material digital, a ser disponibilizado na WEB ou em CD, de apoio para ensino-aprendizagem de Geometria;

- animações Flash de definições e de teoremas centrais, de modo a colocar em evidência as idéias que fundamentam as argumentações dedutivas do conteúdo em questão;

- coleção de problemas, com diferentes graus de complexidade (problemas de construção, de lugar geométrico, de otimização), acompanhados de figuras dinâmicas manipuláveis e de acessos a "dicas de resolução" para casos de dificuldade no avanço da resolução. A resolução dos problemas pressupõe construções e explorações em software de geometria dinâmica.

- coleção de soluções dos problemas, acompanhadas de discussão de dificuldades (as soluções serão disponibilizadas após a publicação das produções dos alunos nos webfólios)

Entre os objetos já desenvolvidos aparece um protótipo de jogo com palitos de fósforo (figura 1). A manipulação dos palitos com a intenção de formar figuras geométricas em quebra-cabeças requer o uso de lógica e estratégia para resolução dos desafios propostos enquanto trabalha conceitos geométricos de polígonos simples como quadrado, triângulo, retângulo, por exemplo.

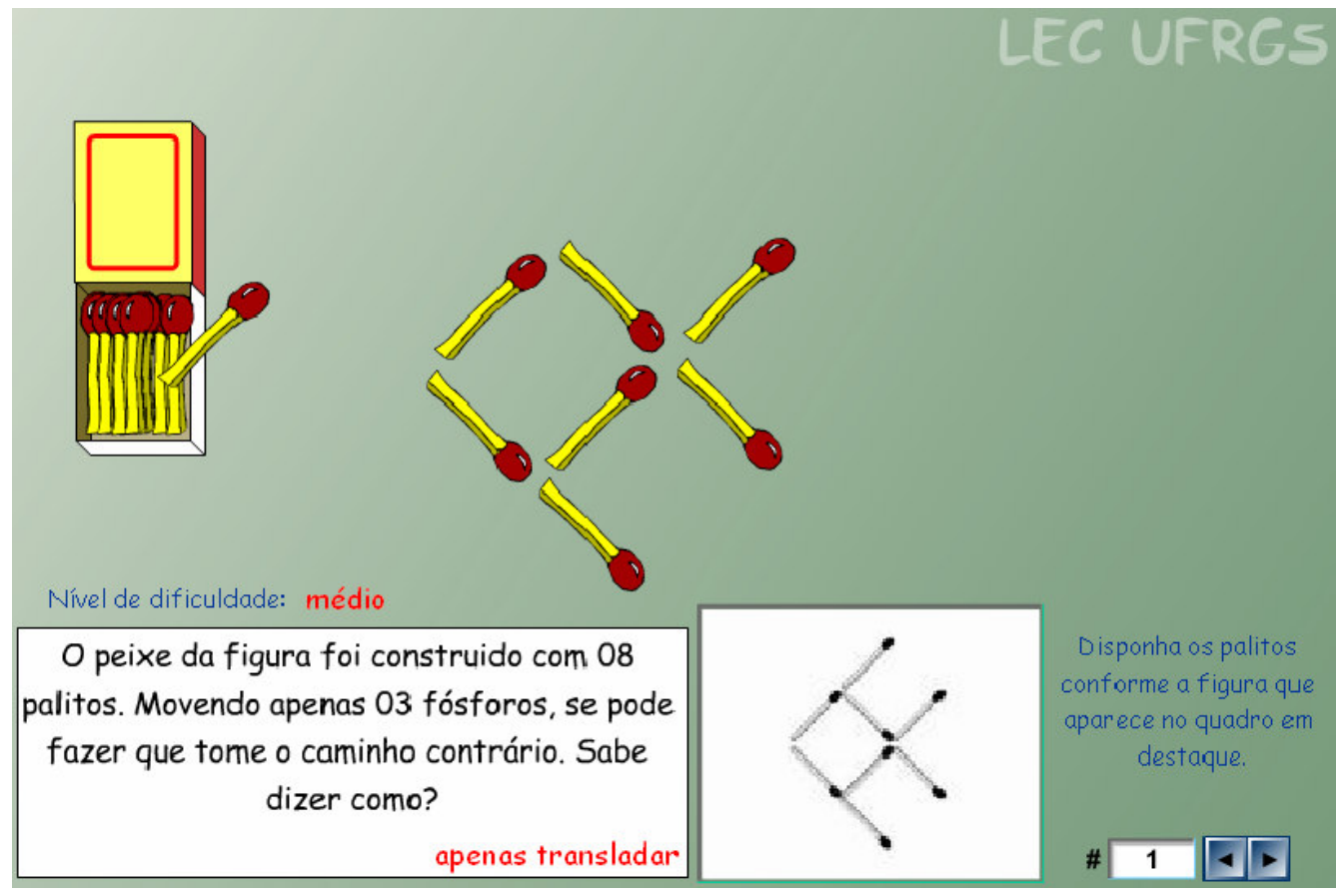

Figura 1: <http://fabricavirtual.lec.ufrgs.br/fosforos.htm> 
Comparar a utilização de diferentes grades, variando a unidade de medida de área, para obter as medidas de diversas superfícies poligonais. O desenho (figura 2) representa apenas uma das múltiplas telas que compõe a atividade. Essa atividade permitirá que os estudantes tirem conclusões a respeito da necessidade de estabelecer unidades de medida e também permitirá que os mesmos construam, via transformações dos objetos, métodos gerais para a determinação das medidas das superfícies poligonais.

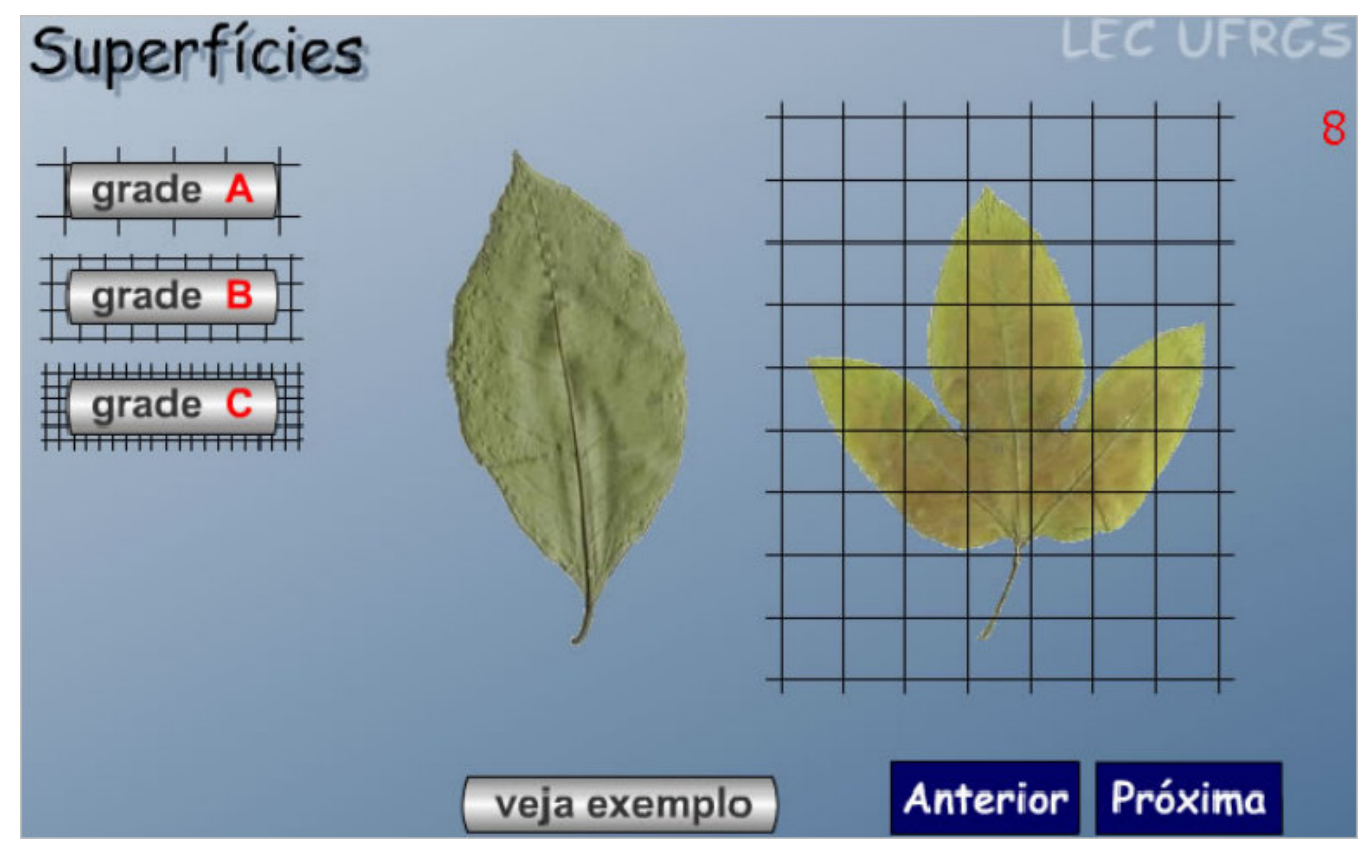

Figura2: <http://mdmat.psico.ufrgs.br/comparando_areas.htm >

Alguns desafios propostos que podem ser observados em animações em CabriJava (figura 3) que partem de experimentos concretos. As animações, por si só, não são suficientes para se chegar a uma resposta ou a uma generalização desejada para a questão. Além da manipulação, permitida nessas animações, a teoria envolvida na questão e as trocas com os colegas e com os tutores é que levam ao aprendizado.

- Para calcular a área de uma figura basta conhecer seu perímetro?

- Se duas figuras tem a mesma área, tem também o mesmo perímetro?

- Dois sólidos que têm a mesma superfície tem o mesmo volume?

- Se dois sólidos tem o mesmo volume, tem a mesma superfície?

- Qual a figura plana, fixado um perímetro (isoperímetro), que possui a maior área? 


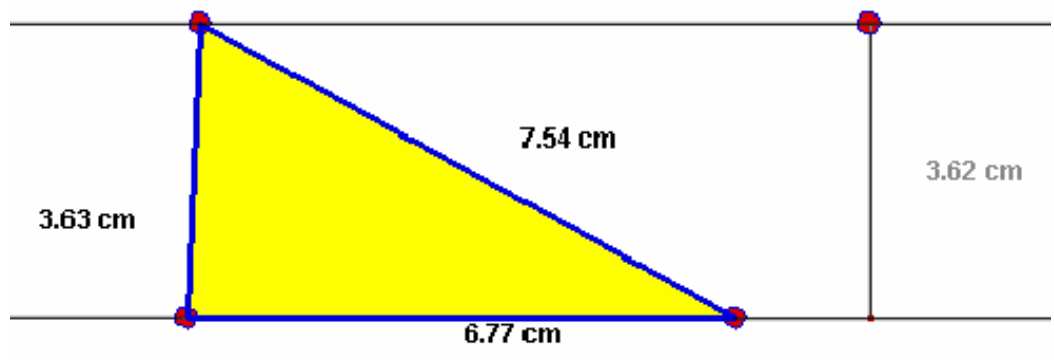

Applet created with CabriJava

Figura3: <http://mdmat.psico.ufrgs.br/experimentos/>

Outros objetos, como os representados nas figuras 4 e 5, também podem auxiliar os estudantes na aprendizagem de conceitos geométricos.

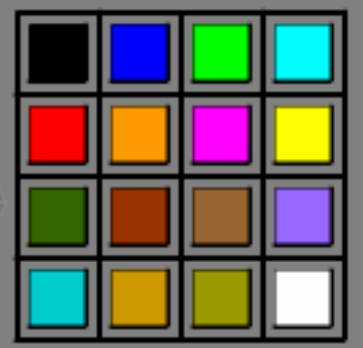

Figura 4: <http://mdmat.psico.ufrgs.br> 


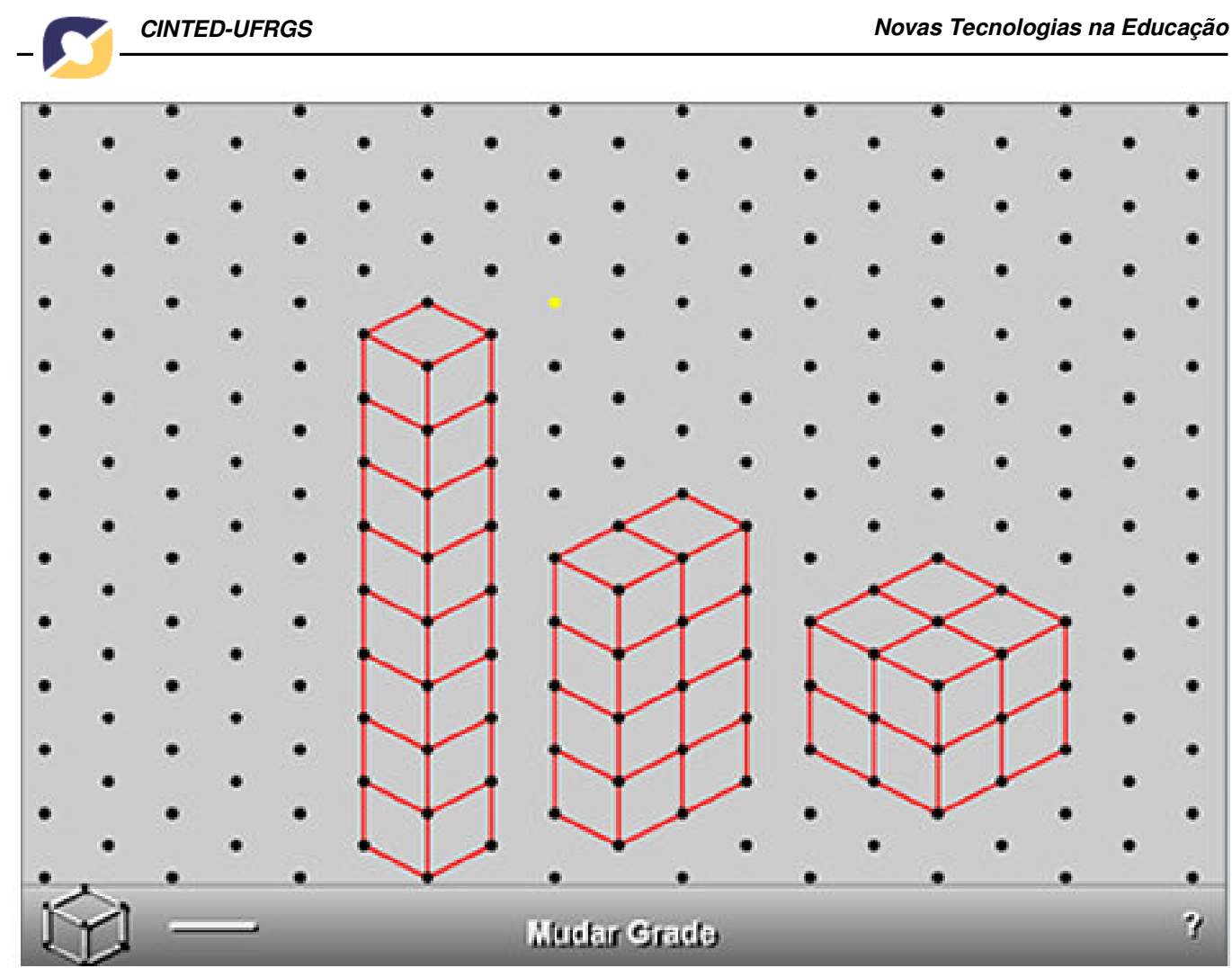

Figura 5: Fábrica de Cubos

Particularmente, nesses dois objetos, a ênfase é auxiliar o estudante a visualizar objetos que simulam uma visão tridimensional, como representado nas figuras 5, 6 e 7 .

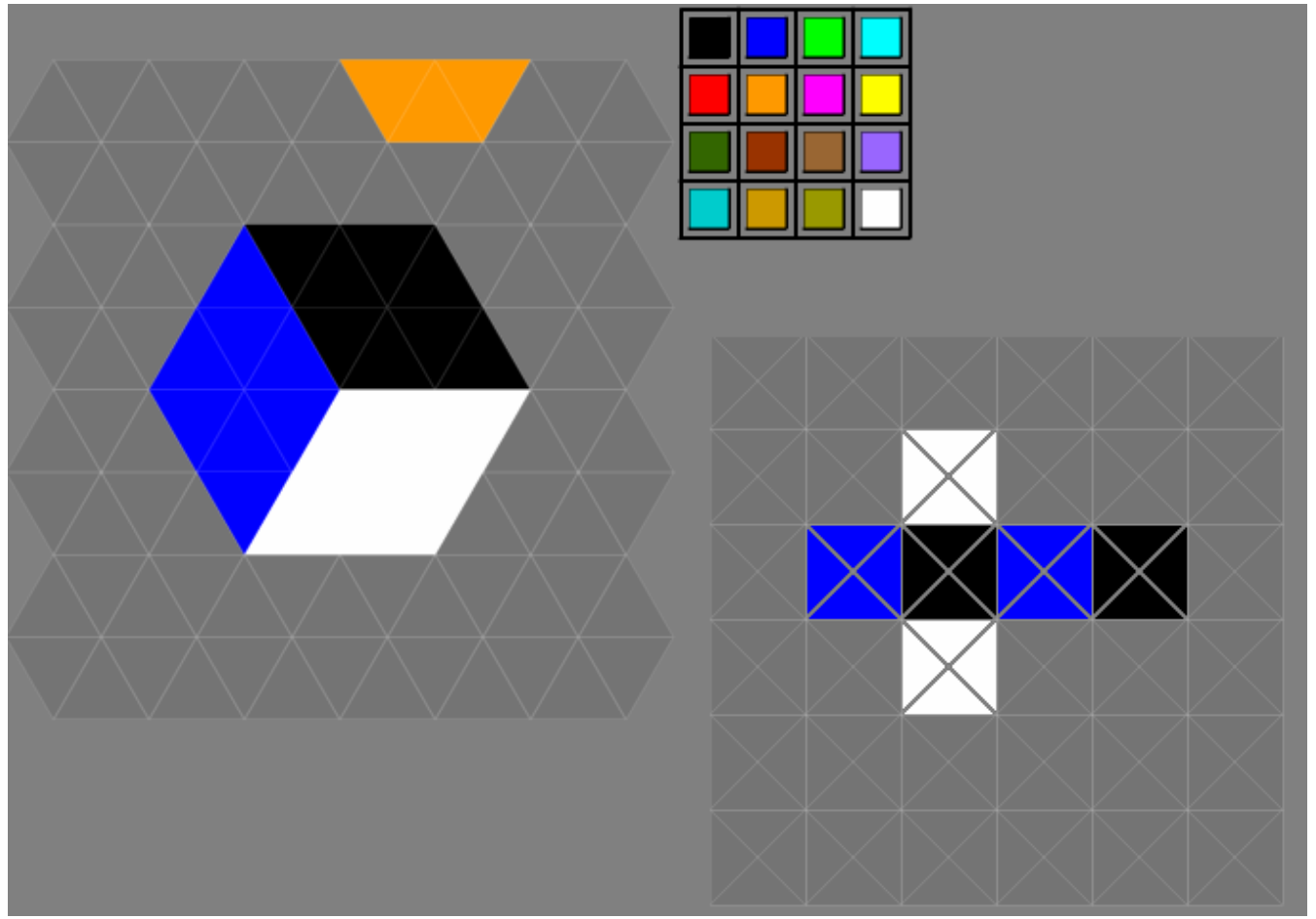

Figura 6: <http://mdmat.psico.ufrgs.br> 


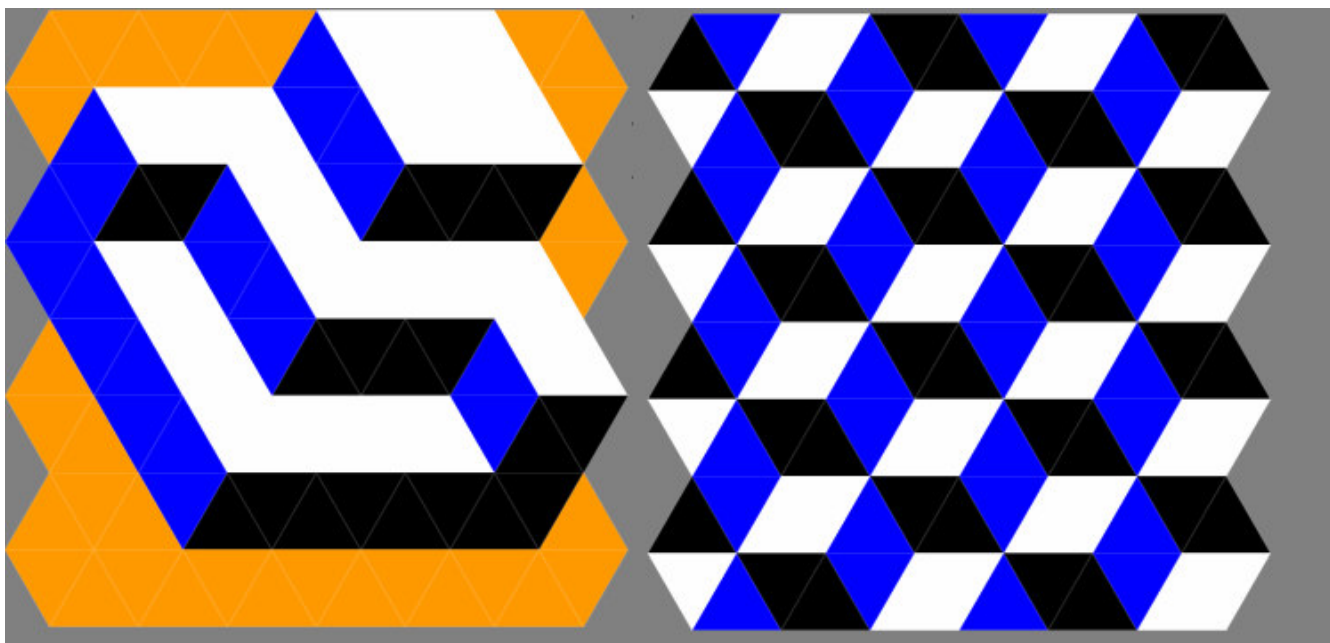

Figura 7: <http://mdmat.psico.ufrgs.br>

\section{Conclusão}

Com uma equipe pequena e, inicialmente, com pouca experiência em flash e em programação, o processo para chegar nas definições e nas características que os objetos e módulos deveriam possuir foi longo. No entanto, as dificuldades técnicas foram sendo superadas aos poucos enquanto outras iam surgindo. Nesse processo, o ambiente que abriga os diversos objetos está adquirindo um formato mais definido na medida em que a equipe ganha experiência. Em função disso, esperamos que a criação de objetos se torne expressiva. Esses objetos e módulos já foram utilizados e testados em situações de ensino-aprendizagem, e tal fato tem permitido que, mesmo objetos já desenvolvidos em uma versão funcional, recebam novos elementos, resultantes da observação de estudantes e professores que deles fazem uso.

O ambiente está em construção e servirá como um repositório de objetos matemáticos, mas também, como fonte de referência de pesquisa e desenvolvimento para novos objetos de aprendizagem. Vários módulos estão sendo incorporados e outros estão em fase inicial de desenvolvimento, como os objetos representados pelas figuras 4 e 5 .

Em termos de perspectiva, a equipe planeja dar continuidade ao desenvolvimento de novos objetos voltados para o ensino-aprendizagem de conceitos matemáticos. Para isso contamos com estudantes do Curso de Licenciatura em Matemática, os principais colaborares e desenvolvedores nesse processo. Igualmente importante, em nosso trabalho favorecemos a testagem dos materiais junto à estudantes e professores dos ensinos Básico e Superior. Isso tem contribuído não somente para a melhoria e aperfeiçoamento dos objetos criados pela equipe, como também tem se mostrado como uma rica fonte de idéias para o desenvolvimento de novos objetos de aprendizagem.

\section{Referências}

BASSO, M. V. A. Espaços de aprendizagem em rede: novas orientações na formação de professores de matemática. Tese de Doutorado. CINTED/PGIE. Universidade Federal do Rio Grande do Sul. Porto Alegre, 2003. Disponível em: http://lec.psico.ufrgs.br/ mbasso/tese/ Acesso online em nov/2006

CASTELNUOVO, E. e BARRA, M. Matematica nella realtà. Torino: Bollati Boringhieri, Torino, 1976. 
FAGUNDES, Léa da Cruz. Aprendizes do futuro: as inovações começaram. Coleção Informática para a Mudança na Educação. MEC/ SEED/ ProInfo, 1999.

MOISE, edwin e. DOWNS, jr. FLOYD 1. Geometria moderna. São Paulo: Edgard Blucher, c1971. vol. 1 e 2

Colégio de Aplicação da UFRGS. PROJETO AMORA. Disponível em: http://amora.cap.ufrgs.br. Acesso online em nov/2006.

RIVED. Rede Interativa Virtual de Educação. Disponível em http://rived.proinfo.mec.gov.br/. Acesso online em nov/2006. 